\title{
BIODEGRADASI ZAT WARNA NAPHTOL BLUE BLACK MENGGUNAKAN BIOSISTEM HORIZONTAL
}

\author{
Y. P. Mau ${ }^{1 *}$, I W. B. Suyasa ${ }^{1,2}$, I. E. Suprihatin ${ }^{1,3}$ \\ ${ }^{1 *}$ Prodi Magister Kimia Terapan, FMIPA Unud, Denpasar, Bali-Indonesia \\ ${ }^{2,3}$ Prodi Kimia, FMIPA Unud, Denpasar, Bali-Indonesia \\ E-mail : yesarelapm9393@yahoo.com
}

\begin{abstract}
ABSTRAK
Warna naphtol blue black (NBB) banyak digunakan dalam pewarnaan kain pada industry rumah tangga. Kegiatan tersebut banyak menghasilkan air limbah yang mengandung zat warna yang mencemari linkungan perairan. Pengembangan biosistem horizontal dengan menambahkan konsorsium mikroorganisme untuk meningkatkan kinerja biosistem adalah alternative penanganan limbah cair. Penelitian ini bertujuan untuk menentukan suspensi aktif terbaik yang akan digunakan dalam pengolahan limbah NBB, kemampuan biosistem horizontal dalam menurunkan konsentrasi NBB. Proses pengolahan zat warna NBB pada penelitian ini menggunakan bak biosistem horizontal dengan adanya tanaman Typha angsutifolia serta penambahan suspensi aktif terbaik. Sumber suspensi aktif terbaik yang diperoleh dari Jalan Pulau Batanta . Potensi pertumbuhan konsorsium mikroba yang dihasilkan mencapai nilai pertumbuhan biomassa (MLVSS) sebesar 2386,7 mg/L. Berdasarkan hasil pengolahan limbah, biosistem horizontal efektif dalam menurunkan konsentrasi NBB 79,82\%. Kapasitas dalam menurunkan konsentrasi NBB adalah 41, $647 \mathrm{mg} / \mathrm{L} / \mathrm{m}^{3}$ jam. Dari hasil penilitian ini dapat disimpulkan bahwa biosistem horizontal mampu menurunkan konsentrasi NBB pada limbah zat warna.
\end{abstract}

Kata kunci: biosistem horizontal, biodegradasi, naphtol blue black, Typha angustifolia

\begin{abstract}
The color of naphtol blue black (NBB) is widely used in fabric dyeing in the household industry. The activity produces a lot of wastewater containing dyes that pollute the waters. The development of horizontal biosystem by adding a consortium of microorganisms to improve the performance of biosystem is an alternative handling of liquid waste. This study aims to determine the best active suspension to be used in treating NBB waste, the ability of horizontal biosystem in decreasing the concentration of NBB. The horizontal biosystem is conctructed of a $0.01 \mathrm{~m}^{3}$ tub containing Typha angsutifolia plant enriched with the best active suspension. The best active suspension source was the sludge collected from Batanta. The growth potential of the resulting microbial consortium achieved a biomass growth value (MLVSS) of $2386.7 \mathrm{mg} / \mathrm{L}$. The results show that the horizontal biosystem is effective in reducing the concentration of NBB is $79.82 \%$. The Capacity of the in reducing the concentration of NBB is $41,647 \mathrm{mg} / \mathrm{L} / \mathrm{m}^{3}$ hour. This study concludes that the horizontal biosystem is able to reduce the concentration of NBB in the dye waste.
\end{abstract}

Keywords: horizontal biosystem, biodegradation, naphtol blue black, Typha angustifolia

\section{PENDAHULUAN}

Pemanfaatan zat warna khususnya NBB dalam usaha pencelupan mengancam kelestarian lingkungan perairan. Ancaman tersebut karena limbah yang dihasilkan tidak diolah hingga aman dibuang ke lingkungan. Kebanyakan usaha pencelupan menggunakan zat warna sintetik yang ekonomis dengan daya toksik yang tinggi (Ferkous, et al., 2015).
Naphtol blue black (NBB) merupakan salah satu contoh dari senyawa azo. Senyawa ini secara luas telah digunakan oleh industri tekstil untuk pencelupan kain, nilon, sutra, dan batik (Ferkous, et al., 2015). Pewarna NBB merupakan kompleks diazo yang memilik stabilitas yang tinggi (Luo dan Hepel, 2001). Oleh karena itu senyawa ini tidak mudah terdegradasi, jika terdegradasi, membutuhkan waktu yang cukup lama. Bila terlalu lama berada di lingkungan akan menjadi sumber pencemar 
karena sifatnya yang karsinogenik dan mutagenik (Ferkous, et al., 2015). Oleh karena itu, pengolahan limbah zat warna ini sangat penting untuk dilakukan.

Salah satu teknik untuk menguraikan senyawa organik menjadi senyawa yang lebih sederhana adalah dengan biosistem. Pengolahan limbah secara biologi (biosistem) yaitu dengan memanfaatkan mikroorganisme untuk mendegradasi molekul zat warna tekstil yang memiliki struktur kompleks menjadi molekul yang lebih sederhana (Manurung, et al., 2004).

Unit pengolahan biosistem adalah pengolahan filtrasi dari pasir dan bebatuan yang dipadukan dengan penyerapan tanaman maupun perombahakan mikroba pada rizosfer akar akan memberikan hasil efektif bagi pemanfaatan kembali air limbah. Akar tanaman memberikan lingkungan yang cocok untuk pertumbuhan mikroba (Suprihatin, et al., 2012). Salah satu tanaman yang digunakan dalam penelitian ini adalah cattail (Typha angustifolia). Tumbuhan ini juga mempunyai rizom serta berbentuk panjang dan ramping. Tumbuhan Typha angustifolia memiliki rhyzosfera merupakan sistem perakaran yang banyak dapat menyerap zat organik di badan air. Pengolahan air limbah domestik dengan proses lahan basah buatan yang menggunakan tumbuhan Typha angustifolia dapat penyisihan kandungan pencemar dalam air limbah dengan waktu tinggal 3 sampai dengan 15 hari, efisiensi penyisihan COD 77,6\% - 91,8\% (Hidayah dan Aditya, 2010).

Penelitian terdahulu, biosistem tanaman digunakan untuk pengolahan limbah pencucian rumput laut dengan penambahan mikroorganisme aktif mampu menurunkan kadar COD sebesar 117,32 mg/L selama 8 jam pengolahan (Suyasa dan Dwijani, 2015).

Berdasarkan dari beberapa penelitian terdahulu, belum pernah dilakukan penelitian menggunakan biosistem horizontal dalam mendegradasi zat warna NBB dengan tanaman Typha angustifolia, oleh sebab itu dilakukan penelitian ini untuk mengetahui kemampuan biosistem horizontal dalam mendegradasi zat warna NBB. Dari kombinasi teknik pengolahan limbah yang dirancangkan secara ekonomis dengan menggunakan bahan-bahan yang sederhana, murah, dan teknologi yang aplikatif, sehingga diharapkan teknik ini dapat diaplikasikan dengan mudah oleh industri teksil supaya limbah yang dilepaskan tidak mencemari lingkungan.

\section{MATERI DAN METODE}

\section{Bahan}

Bahan-bahan yang diperlukan dalam penelitian ini antara lain: tanaman Typha angustifolia, pasir dan koral, zat warna naphtol blue black, larutan glukosa, $\mathrm{K}_{2} \mathrm{HPO}_{4}, \mathrm{KH}_{2} \mathrm{PO}_{4}$, $\left(\mathrm{NH}_{4}\right)_{2}\left[\mathrm{Fe}\left(\mathrm{SO}_{4}\right)_{2}\right] .6 \mathrm{H}_{2} \mathrm{O}, \mathrm{MgSO}_{4}, \mathrm{FeSO}_{4}$, ekstrak ragi, akuades, $\mathrm{HgSO}_{4}, \mathrm{H}_{2} \mathrm{SO}_{4}, \mathrm{~K}_{2} \mathrm{Cr}_{2} \mathrm{O}_{7}$, reagen perak sulfat-asam sulfat $\left(\mathrm{Ag}_{2} \mathrm{SO}_{4} \mathrm{H}_{2} \mathrm{SO}_{4}\right)$, indikator ferroin, dan larutan $\mathrm{Fe}\left(\mathrm{NH}_{4}\right)_{2}\left(\mathrm{SO}_{4}\right)_{2}$.

\section{Peralatan}

Alat-alat yang digunakan dalam penelitian ini antara lain: plastik klip, ember dan termos es, peralatan gelas untuk pembibitan, bak kaca ukuran $60 \mathrm{~cm} \times 30 \mathrm{~cm} \times 30 \mathrm{~cm}$, toples 5 L, aerator, pipa, saluran sampling sport, cawan penguap, tanur (furnace), timbangan merk OHAUS Galaxy 400, erlenmeyer, refrigerator, gelas beker, labu ukur, pipet, labu refluks, kondensor, desikator, oven, peralatan gelas kimia, pipet volume 1, 10, dan $25 \mathrm{ml}$, pipet tetes, ball filter, kertas saring Whatman Grade 42, cawan Gooch, spektrofotometer UV-Vis 1800 Shimadzu, sentrifus, dan penangas (proses refluks).

\section{Cara Kerja}

Penelitian ini dilakukan dalam beberapa tahapan penelitian yaitu penyiapan tanaman Typha angustifolia pada petak penyerap (ekosistem lahan basah), sampling sedimen lumpur aktif, pembibitan (Seeding) lumpur aktif yang diambil dari tiga lokasi berbeda yaitu di Desa Pemogan, Denpasar Selatan. Pembibitan adalah tahap pertumbuhan mikroorganisme dari sedimen lumpur yang diambil dari selokan yang tercemar limbah pencelupan. Kemudian pertumbuhan mikroorganisme dilihat dengan mengukur nilai MLVSS-nya. Pengukuran nilai MLVSS dilakukan sebanyak 3 kali pengulangan untuk masingmasing sampel sedimen lumpur dengan rentang waktu setiap 1 hari sampai menunjukkan adanya peningkatan nilai MLVSS. Data yang diperoleh diplot antara nilai MLVSS dengan waktu pertumbuhan mikroba. Bibit sedimen yang paling cepat tumbuh hingga mencapai fase eksponensial dan memiliki nilai MLVSS yang tinggi (densitas mikrobanya banyak), dipilih sebagai suspensi terbaik dalam pengolahan limbah yang mengandung zat warna NBB. Pengamatan juga dilakukan dengan mengukur nilai $\mathrm{pH}$ dan kadar oksigen terlarut 
(DO) selama pertumbuhan isolat bakteri. Selanjutnya bibit mikroorganisme yang telah siap digunakan dalam pengolahan limbah pencelupan (Atlas dan Barta,1987).

Untuk konstruksi unit biosistem horizontal berukuran $60 \mathrm{~cm} \quad$ x $30 \mathrm{~cm} \quad$ x $30 \mathrm{~cm}$ dan dilengkapi dengan tabung tempat pengambilan sampel. Bak perlakuan diisi dengan batu koral ukuran $5 \mathrm{~cm}$ setinggi $20 \mathrm{~cm}$ pada sisi kiri dan sedikit koral kecil berukuran $0,5 \mathrm{~cm}$ pada sisi kanan dan di tengah diisi pasir berukuran 1-5 $\mathrm{mm}$. Koral dan pasir yang digunakan terlebih dahulu dicuci sampai bersih. Kemudian di tengah-tengah ditanami tumbuhan Typha angustifolia sebanyak hingga sebagian besar lapisan itu terisi oleh rizosfer. Tanaman diadaptasi selama 2 minggu. Volume air limbah artificial zat warna NBB yang diolah ke biosistem horizontal adalah $10 \mathrm{~L}$. Konsentrasi limbah artificial zat warna NBB yang diolah adalah $250 \mathrm{mg} / 10 \mathrm{~L}$ dengan menimbang 250 $\mathrm{mg}$ zat warna NBB secara teliti kemudian dengan 10 L akuades. Limbah artificial zat warna NBB diolah dengan sistem batch dengan membiarkan limbah merendam tanaman selama 1, 2, 3 sampai 4 hari. Sampel di ambil dan diuji konsentrasi NBB-nya dengan Spektrofotometer UV-Vis. Bak pengolahan biosistem horizontal dapat dilihat pada Gambar 1.

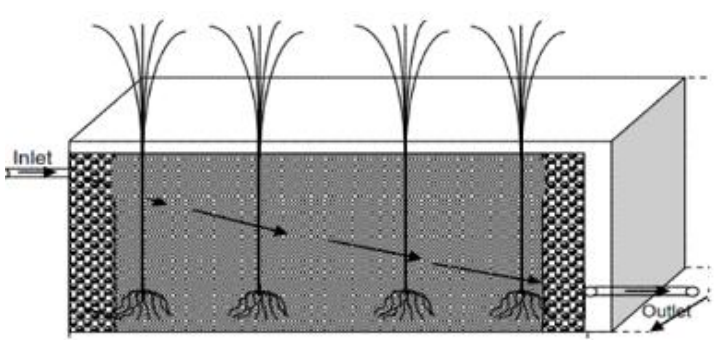

Gambar 1. Skema biosistem horizontal yang digunakan pada penelitian

Data yang diperoleh dianalisis kemampuan biositem horizontal dalam menurunkan kadar NBB. Kemampuan biosistem horizontal tersebut dapat dilihat berdasarkan efektivitas dan kapasitasnya. Efektivitas pengolahan dari biosistem horizontal dihitung persentase penurunan konsentrasi NBB selama proses pengolahan. Hasil pengolahan dikatakan efektif apabila persentase melebihi $50 \%$. Kapasitas pengolahan ditentukan untuk waktu tinggal yang menghasilkan efektifitas tertinggi. Efektivitas ditentukan berdasarkan persamaan berikut (Metcalf dan Eddy, 1991):
$\%$ Efektivitas $=\frac{\left(C_{a}-C_{t}\right)}{C_{a}} \times 100 \%$

Keterangan :

$\mathrm{C}_{\mathrm{a}}=$ konsentrasi NBB awal (mg/L)

$\mathrm{C}_{\mathrm{t}}=$ konsentrasi NBB akhir (mg/L) (pada waktu tertentu).

Kapasitas $=\frac{\left(C_{a}-C_{t}\right)}{V_{\cdot t R}}$

Keterangan :

$\mathrm{C}_{\mathrm{a}}=$ konsentrasi NBB awal (mg/L)

$\mathrm{C}_{\mathrm{t}}=$ konsentrasi NBB akhir (mg/L) (dengan waktu tinggal yang paling efektif).

\section{HASIL DAN PEMBAHASAN}

\section{Penentukan Sumber Suspensi Aktif Terbaik dari Beberapa Sampel Sedimen}

Pembibitan (seeding) adalah tahap pertumbuhan mikroba dari sedimen yang disampling dari selokan tercemar limbah pencelupan. Tujuan pembibitan tersebut untuk memperoleh waktu optimum dari populasi dan aktivitas mikroba sebelum dituangkan ke dalam bak pengolahan biosistem horizontal. Dalam mengamati pertumbuhan mikroorganisme, parameter yang digunakan adalah MLVSS. Pengukuran MLVSS ini bertujuan untuk memperoleh bibit inokulum terbaik yang mampu beradaptasi pada media selektif yang akan digunakan untuk mengolah limbah zat warna NBB. Hasil analisis kadar MLVSS selama proses pembibitan (seeding) suspensi aktif dari tiga lokasi yang ditentukan dalam waktu 5 hari disajikan pada Gambar 2.

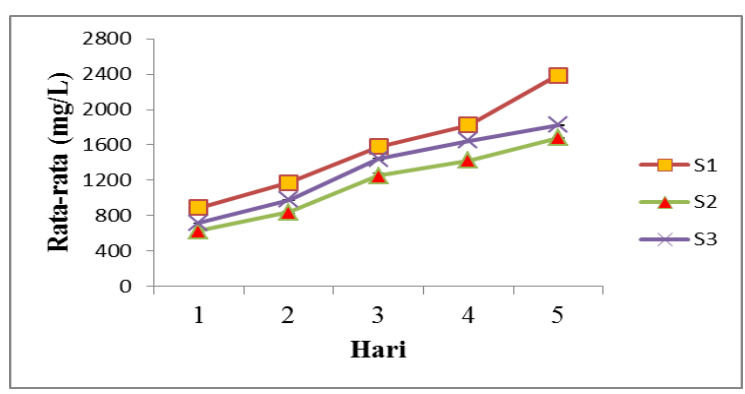

Gambar 2. Rata-Rata Nilai MLVSS Selama Proses Pembibitan dengan Waktu Pengolahan Selama Lima Hari

Gambar 2 menunjukkan bahwa S1 hingga hari ke-5 mencapai nilai MLVSS tertinggi dibandingkan S2 dan S3 yaitu sebesar $888,33-2386,70 \mathrm{mg} / \mathrm{L}$, sedangkan $\mathrm{S} 2$ dan S3 berturut-turut sebesar $630,00-1678,00 \mathrm{mg} / \mathrm{L}$ dan 
716,00-1822,70 mg/L. Terlihat S1 pada hari ke-5 mampu mencapai nilai MLVSS melebihi $2000 \mathrm{mg} / \mathrm{L}$. Adapun nilai MLVSS melebihi $2000 \mathrm{mg} / \mathrm{L}$ menunjukkan tingkat pertumbuhan mikroorganisme dalam lumpur aktif memasuki fase ekselerasi, yaitu suatu kondisi dimana mikroorganisme mengalami penurunan waktu generasi dan peningkatan laju pertumbuhan sehingga mikroorganisme mampu melakukan aktivitas dalam menguraikan bahan organik maupun anorganik yang ada (Sudaryati, et al., 2011). Perbedaan laju pertumbuhan biomassa ini juga disebabkan karena faktor lingkungan, oleh karena itu jenis dan keberagaman mikroorganisme yang terdapat pada masing-masing sedimen berbeda tergantung sedimen berasal. Mikroba S1 mampu beradaptasi dengan cepat dalam media selektif, karena kondisi lingkungan perairan yang tercemar dengan kandungan bahan organik tinggi akan tercipta suasana yang sesuai bagi mikroorganisme untuk menggunakan bahan organik tersebut dalam proses metabolismenya (Mukono, 2000).

Dalam proses pembibitan (seeding) lumpur aktif juga dianalisis nilai $\mathrm{pH}$ dan $\mathrm{DO}$ (ketersediaan oksigen terlarut) untuk mengetahui keterkaitan kedua parameter tersebut dalam proses pembibitan. Hasil yang diperoleh semakin lama waktu perlakuan maka nilai $\mathrm{pH}$ meningkat dan nilai DO menurun. Peningkatan nilai $\mathrm{pH}$ disebabkan karena adanya amonia $\left(\mathrm{NH}_{3}\right)$ yang polar pada proses degradasi kandungan bahan organik dalam larutan zat warna NBB sehingga sangat mudah larut dalam air. Kondisi ini berhubungan dengan reaksi biologis (proses penguraian) yang terjadi oleh mikroorganisme terhadap nutrien yang diberikan seperti glukosa, $\mathrm{MgSO}_{4}, \mathrm{~K}_{2} \mathrm{HPO}_{4}, \mathrm{KH}_{2} \mathrm{PO}_{4}$, ragi, dan $\left(\mathrm{NH}_{4}\right)_{2}\left[\mathrm{Fe}\left(\mathrm{SO}_{4}\right)_{2} \cdot 6 \mathrm{H}_{2} \mathrm{O}\right.$. Peningkatan nilai $\mathrm{pH}$ dari netral menuju basa ini juga disebabkan oleh adanya masukan bahan nutrien yang sebagian besar bersifat basa ke dalam bibit lumpur. Penurunan DO disebabkan karena adanya pemakaian oksigen oleh mikroorganisme untuk proses respirasi sehingga pertumbuhan mikroorganisme tetap berlangsung bahkan terjadi peningkatan. Oksigen juga diperlukan oleh mikroorganisme dalam penguraian nutrien dan bahan organik selama proses pembibitan suspensi aktif, oleh sebab itu untuk menunjang ketersediaan oksigen terlarut diperlukan sistem aerasi selama proses pembibitan maupun pengolahan limbah secara aerob (Suyasa, 2015).

\section{Pengaruh Waktu Perlakuan Biosistem Horizontal Terhadap Penurunan Konsentrasi NBB}

Aplikasi biosistem horizontal untuk mendegradasi konsentrasi NBB selama empat hari telah berhasil menurunkan konsentrasi zat warna tersebut. Data penurunan konsentrasi NBB tersebut disajikan pada Tabel 1 dan Gambar 3.

Tabel 1. Kadar NBB pada berbagai waktu berbeda

\begin{tabular}{|c|c|c|c|}
\hline \multirow{2}{*}{$\begin{array}{l}\text { Waktu } \\
\text { (hari) }\end{array}$} & \multicolumn{2}{|c|}{ Kadar NBB } & \multirow{2}{*}{$\begin{array}{c}\text { Penurunan } \\
\text { Kadar NBB } \\
\text { rata-rata } \\
(\mathrm{mg} / \mathrm{L})\end{array}$} \\
\hline & $\begin{array}{c}\text { Rata-rata } \\
(\mathrm{mg} / \mathrm{L})\end{array}$ & SD & \\
\hline 0 & $25,045^{\mathrm{a}}$ & 0,028 & - \\
\hline 1 & $15,876^{\mathrm{b}}$ & 0,205 & 9,169 \\
\hline 2 & $5,054^{\mathrm{c}}$ & 0,043 & 19.991 \\
\hline 3 & $1,522^{\mathrm{d}}$ & 0,043 & 23,523 \\
\hline 4 & $0,342^{\mathrm{e}}$ & 0,057 & 24,703 \\
\hline
\end{tabular}

Keterangan :

- Nilai rata-rata perlakuan yang diikuti oleh notasi huruf yang sama, dinyatakan tidak berbeda signifikan.

- Nilai rata-rata perlakuan yang diikuti oleh notasi huruf yang berbeda, dinyatakan berbeda signifikan.

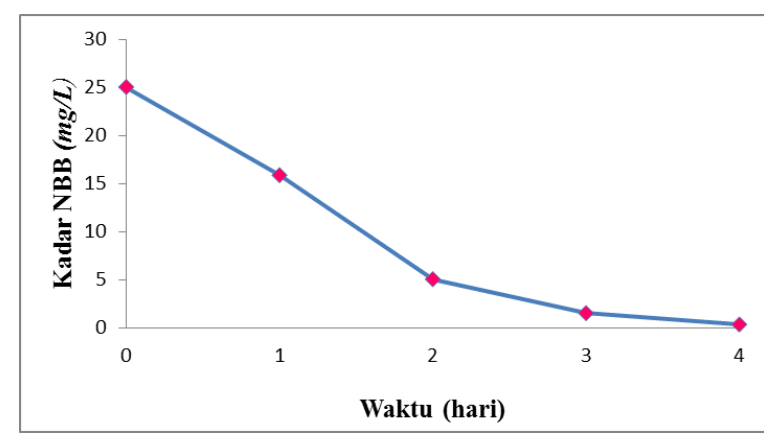

Gambar 3. Kurva Waktu Perlakuan Biosistem Horizontal terhadap konsentrasi NBB

Berdasarkan Tabel 1 dan Gambar 3 selama 2 hari pengolahan konsentrasi NBB mengalami penurunan yang sangat tajam dari awal pengolahan hingga hari ke-2 yaitu sebesar $19.991 \mathrm{mg} / \mathrm{L}$, sedangkan pada hari ke-3 hingga ke-4 penurunan konsentrasi NBB mulai berkurang dengan sisa konsentrasi NBB pada hari ke-4 sebesar $0,342 \mathrm{mg} / \mathrm{L}$. Penurunan konsentrasi NBB pada saat pengolahan disebabkan adanya beberapa proses yang terjadi pada biosistem horizontal tersebut. Adanya aktivitas mikroba yang ditambahkan, 
penyerapan oleh material alam (pasir dan koral), serta penyerapan oleh tanaman Typha angustifolia (Hidayah dan Aditya, 2010).

Berdasarkan hasil uji mikrobiologi terhadap sedimen yang digunakan dalam biosisem horizontal teridentifikasi adanya bakteri Pseudomonas sp. Menurut Chen, et al., (1999) Pseudomonas sp banyak dikembangkan untuk merombak zat warna azo dengan menggunakan glukosa sebagai sumber karbon. Hal ini disebabkan karena mikroba mendegradasi senyawa-senyawa organik komplek berantai panjang menjadi senyawa yang lebih sederhana, selanjutnya terjadi perubahan warna dari hitam kebiru-biruan menjadi tak berwarna. Penghilangan zat warna terjadi karena pemutusan ikatan kromofor gugus azo pada zat warna NBB. Ketika masuk waktu pengolahan hari ke-3 hingga hari ke-4 terjadi penurunan yang sangat lambat, hal ini disebabkan karena kondisi mikroba mulai kehabisan sumber nutrien dan tidak ada tambahan nutrien lagi sehingga mikroorganisme tidak bisa melakukan pertumbuhan dan proses penguraian akan semakin menurun yang disebut dengan keadaan stasioner. Penurunan konsentrasi NBB disebabkan karena zat warna terdegradasi menjadi senyawa-senyawa yang lebih sederhana yaitu $\mathrm{CO}_{2}$ dan $\mathrm{H}_{2} \mathrm{O}$ oleh aktivitas mikrrorganisme, dimana terjadi perombakan warna azo. Proses perombakan warna azo oleh bakteri pada dasarnya merupakan reaksi redoks yang dikatalisi oleh enzim. Mikroorganisme memerlukan kosubstrat berupa senyawa karbon organik seperti glukosa untuk mempercepat proses azo. Glukosa dalam sistem biologi mengalami proses glikolisis dengan bantuan enzim dehydrogenase menghasilkan enzim koenzim nikotinamida adenine dinukleotida (NADH). Koenzim NADH yang dihasilkan dari proses glikolisis glukosa mentransfer elektron ke zat warna azo yang dikatalisis oleh enzim reductase. Koenzim NADH mengalami reaksi oksidasi menghasilkan $\mathrm{NAD}^{+}$, sedangkan zat warna azo mengalami reduksi menghasilkan senyawa amina aromatic yang tidak berwarna. Selanjutnya pada tahap perombakan aerob, amina aromatik diuraikan lebih lanjut menghasilkan senyawa yang lebih sederhana (Manurung, et al., 2004).

Proses pengolahan fisika secara adsorpsi dilakukan oleh pasir dan koral, karena pasir dan koral memiliki kandungan silika. Proses selanjutnya adalah penyerapan oleh akar tanaman. Tumbuhan akan menyerap unsur-unsur hara yang larut dalam air dan tanah melalui akarnya. Tumbuhan dapat menyerap kontaminan sedalam atau sejauh akar tanaman yang dapat tumbuh (Stefhany et al., 2013). Tanaman yang awalnya segar dan memiliki daun yang lebat,menjadi layu kekuningan. Hal ini membuktikan bahwa tanaman tersebut ikut menyerap NBB sehingga mampu menurunkan konsentrasi NBB dalam limbah. Selain menyerap NBB tanaman Thypa angustifolia ini juga menguraikan zat-zat kontaminan dengan aktivitas mikroba yang berada di sekitar akar melalui proses rhizodegradasi.

\section{Kemampuan Biosistem Horizontal}

Kemampuan biosistem horizontal, dapat dilihat dari dua aspek yaitu efektivitas dan kapasitas biosistem horizontal dalam menurunkan konsentrasi NBB.

Biosistem horizontal efektif dalam menurunkan konsentrasi NBB pada hari ke-2 sebesar 79,82\%. Berdasarkan efektivitas pengolahan limbah tersebut, maka dapat ditentukan kapasitas maksimum bak pengolahan biosistem horizontal dalam menurunkan konsentrasi NBB. Kapasitas biosisem horizontal dalam menurunkan konsentrasi NBB sebesar $41,647 \mathrm{mg} / \mathrm{L} / \mathrm{m}^{3}$ jam. Jadi selama waktu tinggal air limbah 48 jam (2 hari), $0,01 \mathrm{~m}^{3}$ bak pengolahan mampu menurunkan konsentrasi NBB.

\section{SIMPULAN}

Berdasarkan hasil penelitian dan pembahasan, maka dapat disimpulkan sebagai berikut :

1. Suspensi aktif terbaik yang diperoleh berdasarkan laju pertumbuhan dan memiliki pertumbuhan biomassa (nilai MLVSS) tertinggi hingga hari ke-5 adalah dari Pulau Batanta (S1) sebesar 2386,7 mg/L.

2. Biosistem horizontal dengan suspensi aktif mampu menurunkan konsentrasi NBB pada hari ke-2 sebesar 5,054 mg/L.

3. Efektivitas biosistem horizontal dengan suspensi aktif efektif menurunkan konsentrasi NBB pada hari ke-2 sebesar $79,82 \%$. Kapasitas biosistem horizontal dengan volume $0,01 \mathrm{~m}^{3}$, dalam menurunkan konsentrasi NBB sebesar 41,647 $\mathrm{mg} / \mathrm{L} / \mathrm{m}^{3} \mathrm{jam}$ 


\section{UCAPAN TERIMA KASIH}

Penulis mengucapkan terimakasih kepada Dr. Manuntun Manurung, M.S., James Sibarani, S. Si., M. Si., Ph.D., dan Dr. Drs. Ketut Gde Dharma Putra, M. Sc atas masukan dan ide yang telah diberikan.

\section{DAFTAR PUSTAKA}

Atlas, R.M., and Bartha, R., 1987, Microbial Ecology, Fundamental and Applications, California: The Benjamin/Cummings Publishing Company, Inc.

Chen, K., Huang, W.,Wu, J.\& Houng, J., 1999, Microbial decolorization of azo dyes by Proteus mirabilis, Journal of Microbiology and Biotechnology, 23: 686-690.

Ferkous, H., Hamdaoui, O and Merouani, S., 2015, Sonochemical Degradation of Naphtol Blue Black in Water: Effect of Operating Parameters, Ultrasonic Sonochemistr, 26: 40-47.

Hidayah, E. N dan Aditya, W., 2010, Potensi Dan Pengaruh Tanaman Pada Pengolahan Air Limbah Domestik Dengan Sistem Constructed Wetland, Jurnal Ilmiah Teknik Lingkungan, 2(2): 11-18.

Luo, J.and Hepel, M., 2001, Photoelectrochemical Degradation of Naphtol Blue Black Diazo Dye on $\mathrm{WO}_{3}$ Film Electrode, Electrochemica Acta, 46: 2913-2922.
Manurung, R., Hasibuan, R., Irvan, 2004, Perombakan Zat Warna Azo Reaktif secara Anaerob-Aerob, e-USU Repository (C) 2004 Universitas Sumatera Utara, 1-19.

Metcalf and Eddy,1991, Waste Water Engineering, New York : Mcgraw Hill

Mukono, H.J., 2000, Prinsip Dasar Kesehatan Lingkungan, Surabaya: Universitas Airlangga.

Sudaryati, N. L. G., Kasa, I.W., dan Suyasa, I.W.B., 2011, Pemanfaatan Sedimen Perairan Tercemar Sebagai Bahan Lumpur Aktif Dalam Pengolahan Limbah Cair Industri Tahu, Ecotrophic, 3 (1): $21-29$.

Suprihatin, I.E., Suyasa, I. W. B., and Sulihingyas, W. D., 2012, Rhizodegradation of Oil Waste, Proceedings, ICBB, Denpasar

Suyasa, I. W. B., 2015, Pencemaran Air dan Pengolahan Air Limbah, Denpasar : Udayana University Press.

Suyasa, I. W.B., dan Dwijani,W., 2007, "Kemampuan Sistem Saringan PasirTanaman Menurunkan Nilai BOD dan COD Air Tercemar Limbah Pencelupan", Jurnal Ecotrophic, 2 (1):1-7.

Stefhany, C. A., Sutisna, M., dan Pharmawati, K., 2013, Fitoremediasi Phospat dengan Menggunakan Tumbuhan Eceng Gondok (Eichhornia crassipes) pada Limbah Cair Industri Kecil Pencucian Pakaian (Laundry), Jurnal Institut Teknologi Nasional, 1(1) :1-11. 